\title{
Nematode Composition and Soil Conditions in Plots under a Wheat Crop in Colfax, Washington State
}

\author{
Martin M. Matute ${ }^{1}$, Arron H. Carter ${ }^{2} \&$ Jamie Sherman ${ }^{1}$ \\ ${ }^{1}$ Plant Sciences and Plant Pathology, Montana State University, Bozeman, MT, USA \\ ${ }^{2}$ Department of Crop and Soil Sciences, Washington State University, Pullman, WA, USA \\ Correspondence: Martin M. Matute, Plant Sciences and Plant Pathology Department, Montana State University, \\ Bozeman, MT 59717, USA. Tel: 1-501-626-1639. E-mail: moluwa.matute@gmail.com
}

\author{
Received: June 27, 2015 Accepted: September 4, 2015 Online Published: October 15, 2015 \\ doi:10.5539/jas.v7n11p76 URL: http://dx.doi.org/10.5539/jas.v7n11p76
}

\begin{abstract}
Plant parasitic nematodes have been identified as a major problem to wheat (Triticum aestivum L.) production in the Pacific Northwest (PNW) states of the USA. Nematicide control of these parasites has been successful. We were, however, interested in understanding how the soil nematode-nematode interactions and the nematode-host plant interactions affect nematode populations of different feeding groups and how the soil nematode composition could be used to elucidate soil conditions in a winter wheat crop. Our results revealed that the ratio of the plant-parasite index (PPI) to the maturity index (MI = free-living nematodes) was high, meaning we had higher populations of the herbivorous nematodes than all of the other feeding groups combined. The low populations of the free-living nematodes meant little or no nitrogen mineralization by the bacterivorous and fungivorous nematodes, and also a lack of meaningful predation of the plant-parasitic nematodes by the pest suppressive species i.e omnivores and carnivores. The high plant-parasitic nematode populations and low populations of the free-living nematodes may have also interfered with nutrient uptake by the plants and resulted in stressed soils in the plots studied. Based on our results, farming methods that will reverse the PPI/MI ratio will be a natural and ecologically friendly way of reducing populations of the parasitic nematodes in the wheat plots e.g. rotations and soil amendments. During the different sampling periods, the soil conditions changed from basal, to enriched, and then maturing, based on the nematode composition. Thus the soil nematode composition can be used for the biomonitoring of soil conditions in wheat plots.
\end{abstract}

Keywords: Colfax, wheat, soil, nematodes, biomonitoring

\section{Introduction}

Plant-parasitic nematodes are of great economic importance. However, because most of them live in the soil, they represent one of the most difficult pest problems to identify, demonstrate, and control (Stirling et al., 1998). Plant-parasitic nematodes have been called the farmer's hidden enemy (Sasser, 1989). Their effects are commonly underestimated by farmers, agronomists, and pest management consultants, but it has been estimated that some 10 percent of world crop production is lost as a result of plant nematode damage (Whitehead, 1998). Plant parasitic nematodes have long been recognized as a challenge to crop production (Nicol et al., 2011). It is estimated that, on a global scale, yield loss from nematodes is close to $\$ 80$ billion, which is probably underestimated due to the fact that symptoms of nematode damage are often assumed to be caused by other pest or pathogens or by abiotic stress (Handoo, 1998). Wheat is a major crop of the US and the world, and nematodes are a global threat to that crop. Up to 7 percent of wheat global production has been reported lost annually to the destructive activities of plant-parasitic nematodes (Sasser, 1989).

The importance of plant-parasitic nematodes in crop production in the Pacific Northwest (PNW), USA, has been documented. Smiley et al. (2005) quantified the impact of Heterodera avenae on spring wheat yield in the PNW. They planted spring wheat with or without aldicarb to examine relationships between $H$. avenae and yield under dry land and irrigated conditions in moderately infested fields. They reported that spring wheat yields were negatively correlated with initial populations of $H$. avenae. Aldicarb application improved spring wheat yield by as much as 24 percent. Smiley et al. (2005) also noted that the infective juvenile stage of $H$. avenae reached a peak density during mid-spring and that yield of irrigated annual winter wheat was also negatively correlated with initial density of $H$. avenae. In a recent study, Smiley et al. (2012) reported that the cereal cyst nematode $H$. 
avenae was capable of reducing winter wheat and barley yields by as much as 50 percent in infested soils, for an estimated annual loss of \$4.3 million in the PNW states of Idaho, Oregon, and Washington.

Heterodera avenae and $H$. filipjevi are economically important cyst nematodes that restrict production of cereal crops in the PNW and elsewhere in the world (Yan et al., 2013). For the first time in 2013, Yan et al. (2013) developed species-specific PCR assays to distinguish between these two species. Identification of these two species is critical for recommending and implementing effective management practices (Yan et al. 2013). In a survey by Smiley et al. (2004), they reported that many fields ( 25 percent) cropped more frequently than 2 of 4 years had potentially damaging populations of lesion nematodes. Smiley et al. (2004) noted that the Pratylenchus neglectus density in winter wheat roots was inversely correlated with grain yield, providing the first-derived evidence that Pratylenchus is economically important in dry land field crops in the PNW.

The wheat nematological studies carried out in the PNW have focused on the economics associated with the destructive plant-parasitic nematodes especially the cereal cyst nematodes (H. avenae and H. filipjevi) and the root-lesion nematodes ( $P$. neglectus). Nematode researchers in the PNW have demonstrated that the use of nematicides improve wheat grain yield as compared to control plots (Smiley et al., 2005). While the study by Smiley et al. (2005) associated populations of plant-parasitic nematodes with low wheat grain yield, other nematological studies elsewhere seem to suggest that the nature of the nematode soil food web structure is associated with the pathogenicity of the tissue feeding nematodes (Ferris et al., 2001; Ferris \& Matute, 2003; Yeates, 2003; Bongers \& Ferris, 1999). For example, free-living soil nematodes, on the other hand, are beneficial: bacterial and fungal feeding nematodes contribute to soil fertility by releasing nitrogen in excess of their structural and metabolic demands (Ingham et al., 1985; Ferris \& Matute, 2003; Chen \& Ferris, 1999; Chen \& Ferris, 2000); and omnivorous and carnivorous nematodes are predators that suppress soil pest species e.g. plant-parasitic nematodes (Matute \& Anders, 2012; Matute et al., 2013; Matute, 2013).

Many factors contribute to the general conditions of soils and such factors include the abiotic (e.g. pH, moisture, soil mineralogy, soil management) and the biotic (e.g. nematodes and other invertebrates). Ferris et al. (2001) were able to describe soil conditions using the soil nematode community structure or composition. They elucidated three main soil conditions: Basal Soils-soils with a high C:N ratio, fungal conducive, degraded, etc. and the nematodes associated with such soils are the bacterivorous nematodes of the family Cephalobidae and fungivorous nematodes of the family Aphelenchidae; Enriched Soils- these are disturbed soils, nitrogen-enriched, low $\mathrm{C}: \mathrm{N}$ ratio, and bacterial conducive. The nematodes associated with such soils are the bacterivorous nematodes of the families Rhabditidae and Panagrolaimidae and the fungivorous nematodes of the family Aphelenchoididae; Structured or Matured soils- these are fertile soils, moderate C: N ratio, pest suppressive, etc. Nematodes associated with such soils include free-living nematodes of the colonizer-persister class 3-5, i.e. cp3-5, of the fungivorous, bacterivorous, carnivorous and omnivorous nematodes. Examples of such nematode families include the Prismatolaimidae, Aporcelaimidae, Nygolaimidae, and Dorylaimidae.

Food security is in part dependent on the health status of the soil in which crops are grown. By virtue of their population size and their representation at all trophic levels, soil nematodes are an important tool in the determination of soil conditions. It is our goal to better understand the nematode food web and its implications on wheat production in the PNW. The objective of our study was to understand biotic-biotic interactions in wheat plots and how these interactions in turn affect nematode populations and soil conditions. Specifically we were interested in a) interactions that involved free-living and plant-parasitic nematodes, b) the susceptibility of the host plants to plant-parasitic nematodes, and c) using the soil nematode composition or community structure to ascertain the conditions of soil in the wheat plots.

\section{Materials and Methods}

\subsection{Study Site}

This investigation was carried out in a commercial winter wheat field near Colfax, Whitman County, Washington State, located in the PNW. The plots investigated were grown with winter wheat, seeded in September and harvested in August. The seeds used in this study were the soft white winter wheat cultivar Stephens (CItr 17596; Kronstad et al., 1978), known to be susceptible to the root-knot and root lesion nematodes. Aside the susceptibility, these nematodes have also been associated with a reduction in the yield potential of the wheat cultivar Stephens in the study area. During the period of the investigation, the average surface temperature was $8.94{ }^{\circ} \mathrm{C}$ and the average annual precipitation-rainfall, was $50.8 \mathrm{~cm}$. The wheat was grown according to conventional farming methods. Soil samples were collected at preplant (APS) for baseline data, at mid-season or anthesis (AMS), and at harvest (AHS). This investigation did not include control plots i.e. patches of soil devoid of wheat plants because our focus was on wheat plots and we used our initial sampling as the baseline data. 
Using a soil sampler, soil samples were collected at a depth of $15-20 \mathrm{~cm}$. Ten rows from the wheat plot were selected at random and from each 10 samples were collected. The rows sampled were approximately 10 meters apart. Each sample collected was a composite of 4-6 corers. Each sample was appropriately bagged and transported to the laboratory for nematode extraction and analysis.

\subsection{Soil Nematode Extraction}

Nematodes were extracted from the soil basically as described by Barker (1985). In the laboratory each composite soil sample was homogenized and then subsamples withdrawn for analysis. $100 \mathrm{~mL}$ subsample was withdrawn for nematode analysis. A combination of sieving, decanting, and Baermann funnel methods were used to extract the nematodes. The $100 \mathrm{~mL}$ subsample was transferred onto a container with $10 \mathrm{~L}$ of water, the crumps dissolved and the mixture stirred and left to settle. The supernatant was then filtered through a $60 \mathrm{um}$ and then a $400 \mathrm{um}$ mesh sieve. The retained sample was then transferred onto to a Baermann funnel assemblage and incubated for 72 hours. After the incubation period the first $15 \mathrm{~mL}$ of each sample was tapped and subjected to qualitative and quantitative nematode analysis. Nematodes were identified based on their morphology, especially their feeding mouthparts. Extracted nematodes were identified to the family and genus levels (when possible), under their respective colonizer-persister (C-p; 1-5) class or plant-parasite (P-p; 3-5) class (Bongers, 1990). For the cyst and root-knot nematodes only the juvenile stage 2 (J2) stages were recovered, whereas for other nematode taxa, a mixture of $\mathrm{J} 2$ and adult stages were recovered. Data used for the analysis did not distinguish between juvenile and adult stages, but a count that represented all individuals of a taxon according to feeding groups.

The colonizer-persister (cp) scale is an assignment of free-living taxa of soil and freshwater nematodes to a 1-5 linear scale according to their $\mathrm{r}$ and $\mathrm{k}$ characteristics (T. Bongers \& M. Bongers, 1998), whereas the plant-parasite (P-p) scale assigns the plant-parasitic nematodes on a linear scale of 2-5. There are two gradations of evolutionary strategies due to natural selection, termed the $\mathrm{r}$ - and $\mathrm{k}$ - selection; r-selected individuals or strategists produce many offspring in a short period of time and live in unstable environments, whereas k-strategists produce few offspring in a long period of time and live in stable environments. Lower values of these scales (1-2) represent the r-strategists and the higher values (3-5) represent the k-strategists.

\subsection{Analysis of the Data}

While we were mainly interested in understanding nematode-nematode interactions, nematode-host interactions, and nematode composition related to soil conditions, we carried out six different analyses to be able to elucidate the nature of these interactions. The following analyses were carried out:

1) Metabolic Footprint: We compared the metabolic footprint (Ferris, 2010; Sieriebriennikov et al., 2014) of the plant-parasitic nematodes (target prey), the amplifiable prey (bacterivorous and fungivorous nematodes), and the predators (carnivorous and omnivorous nematodes), to determine their relative contributions to soil physiological processes, especially carbon utilization.

2) Food Web Analysis: The nematode faunal analysis was used to measure the soil health status (basal, enriched or structured) which serves as an ecosystem function index due to nematode-nematode and nematode-host interactions (Sieriebriennikov et al., 2014; Ferris et al., 2001).

3) Nematode Indices: Nematodes were classified by the colonizer-persister (C-p) scale, on the parasitism (P-p) scale, and by feeding type, allowing for the estimation of the maturity index (MI) and the plant parasite index (PPI) (Bongers, 1990; Ferris et al., 2001). Calculation of the MI and PPI include all individuals of a nematode taxon.

The Maturity Index (MI) is a semi-quantitative value which indicates the condition of an ecosystem based on the composition of the free-living 'nematode community' (Bongers, 1989). The Maturity Index for a soil is the weighted mean $\mathrm{cp}$ value of the individuals in a representative soil sample. According to Bongers and Ferris (1999), MI values range from 2.0 in nutrient-enriched disturbed systems to $+/-4.0$ in undisturbed pristine environments.

The Plant-Parasite Index (PPI), is comparable to the MI, but computed only for the plant-feeding nematodes with the rationale that their abundance is determined by the vigor of their host plants which, in turn, is determined by system enrichment. Consequently, under nutrient poor conditions of natural ecosystems, often associated with a high proportion of Tylenchidae (cp2) in the nematode assemblage, the PPI is lower than under enriched agricultural conditions, the inverse of the response of the MI to enrichment (Bongers, 1990; Bongers et al., 1997).

4) Nematode Composition: To efficiently elucidate the soil nematode community structure, the composition of the free-living nematodes and plant-parasitic nematodes were recorded and then subcategorized into their specific 
feeding habits, and C-p and P-p classes, illustrating their relative proportions by feeding groups (Sieriebriennikov et al., 2014).

5) The PPI/MI Ratio: Was used to demonstrate how the value of this calculated ratio impact nutrient availability and nutrient uptake by plants (Bongers et al., 1997), and therefore an indicator of soil conditions.

6) Host Susceptibility: Crops are normally good hosts or susceptible to certain plant nematodes but not others. We determined host status to the plant-parasitic nematodes recovered, by recording the respective taxa populations at preplant (APS) i.e. the initial population $\left(\mathrm{P}_{\mathrm{i}}\right)$ and the population at harvest (AHS) i.e. final population $\left(\mathrm{P}_{\mathrm{f}}\right)$. If $\mathrm{P}_{\mathrm{f}} / \mathrm{P}_{\mathrm{i}}>1$, then the crop was considered a suitable host and susceptible to the parasitic nematode taxa.

\section{Results and Discussion}

\subsection{Soil Nematodes Associated with Wheat Plots in Colfax}

Table 1 summarizes the soil nematodes recovered from the wheat plots in Colfax according to their feeding habits. Four nematode feeding groups were recovered, the herbivores or plant-parasites, the fungivores or fungal feeders, the bacterivores or bacterial feeders, and the omnivores (plant and animal tissue feeders). Of the 11 plant-parasitic nematode genera recovered, the wheat grown was found to be a good host for seven of them $\left(\mathrm{P}_{\mathrm{f}} / \mathrm{P}_{\mathrm{i}}>1.0\right.$ or HS/PS $\left.>1.0\right)$. This means that the nematodes are feeding and reproducing and is also a measure of susceptibility. Based on these values, the planted wheat was most suitable for the reproduction of Helicotylenchus $\left(\mathrm{P}_{\mathrm{f}} / \mathrm{P}_{\mathrm{i}}=48.3\right)$, Trichodorus $\left(\mathrm{P}_{\mathrm{f}} / \mathrm{P}_{\mathrm{i}}=23\right)$, and Heterodera $\left(\mathrm{P}_{\mathrm{f}} / \mathrm{P}_{\mathrm{i}}=3.2\right)$. However, though the cyst nematodes ranked third in terms of susceptibility, their harvest populations were more than eight times those of the spiral nematodes (Helicotylenchus). While a high susceptibility to Helicotylenchus may not necessarily be equated to high pathogenicity, it may however suggest that pathogenicity to wheat attributed to Heterodera in the PNW (Smiley et al., 2005, 2012) could be in combination with Helicotylenchus in fields where it occurs. Female cysts nematodes are macroscopic and easily recognizable as compared to the other plant nematodes that are microscopic and more difficult to identify. It is reasonable to assume that field pathogenicity to wheat crops attributed to parasitic nematodes includes both the readily and not so readily identifiable taxa.

The absence of carnivorous or predatory nematodes in the list of nematodes recovered is attributed to the fact that the wheat plots are disturbed and also suggest that predatory nematodes are more sensitive to disturbance than omnivorous nematodes (Matute \& Anders, 2012; Matute et al., 2013; Matute, 2013). The absence of these predators is expected to result in a proliferation of the prey species. 
Table 1. Soil nematode taxa recovered from soils under wheat cultivation in Colfax. Each value is a mean of 10 replicates (samples) and each sample was a $100 \mathrm{~mL}$ subsample from a homogenized composite sample

\begin{tabular}{|c|c|c|c|c|c|c|c|c|}
\hline $\mathrm{s} / \mathrm{n}$ & Nematode taxa & C-p class & P-p class & Feeding type & APS & AMS & AHS & Host Status hs/ps \\
\hline 1 & Aphelenchoides & 0 & 2 & Herbivores: Ectoparasites & 110.3 & 131 & 40.2 & 0.364 \\
\hline 2 & Helicotylenchus & 0 & 3 & Herbivores: Semi-endoparasites & 0.9 & 0.7 & 43.5 & 48.333 \\
\hline 3 & Heterodera & 0 & 3 & Herbivores: Sedentary parasites & 115.6 & 78.4 & 369.2 & 3.194 \\
\hline 4 & Hoplolaimus & 0 & 3 & Herbivores: Semi-endoparasites & 0.9 & 26.3 & 1.6 & 1.778 \\
\hline 5 & Malenchus & 0 & 2 & $\begin{array}{l}\text { Herbivores: Epidermal/root } \\
\text { hair feeders }\end{array}$ & 0.7 & 83.8 & 1.5 & 2.143 \\
\hline 6 & Meloidogyne & 0 & 3 & Herbivores: Sedentary parasites & 62 & 1 & 1.3 & 0.021 \\
\hline 7 & Pratylenchus & 0 & 3 & Herbivores: Migratory endoparasites & 20.5 & 51.5 & 1.3 & 0.063 \\
\hline 8 & Psilenchus & 0 & 2 & $\begin{array}{l}\text { Herbivores: Epidermal/root } \\
\text { hair feeders }\end{array}$ & 0.9 & 50.6 & 1.3 & 1.444 \\
\hline 9 & Trichodorus & 0 & 4 & Herbivores: Ectoparasites & 0.9 & 0.7 & 20.7 & 23.000 \\
\hline 10 & Tylenchorhynchus & 0 & 3 & Herbivores: Ectoparasites & 19.1 & 50.1 & 35.5 & 1.859 \\
\hline 11 & Tylenchus & 0 & 2 & $\begin{array}{l}\text { Herbivores: } \\
\text { Algal/Lichen/Moss-feeders }\end{array}$ & 101.4 & 317.2 & 24 & 0.237 \\
\hline 12 & Aphelenchus & 2 & 0 & Fungivores & 27.6 & 0.9 & 59.7 & NA \\
\hline 13 & Acrobeloides & 2 & 0 & Bacterivores & 131.8 & 168.8 & 174.2 & NA \\
\hline 14 & Cephalobus & 2 & 0 & Bacterivores & 64.1 & 389.6 & 55.3 & NA \\
\hline 15 & Mesorhabditis & 1 & 0 & Bacterivores & 0.7 & 52.9 & 39.4 & NA \\
\hline 16 & Panagrolaimus & 1 & 0 & Bacterivores & 29.2 & 171.9 & 33.1 & NA \\
\hline 17 & Plectus & 2 & 0 & Bacterivores & 813.9 & 87.6 & 151.8 & NA \\
\hline 18 & Rhabditis & 1 & 0 & Bacterivores & 1.1 & 65.8 & 1.7 & NA \\
\hline 19 & Prionchulus & 4 & 0 & Omnivores & 0.5 & 1.5 & 21.3 & NA \\
\hline 20 & Labronema & 4 & 0 & Omnivores & 0.5 & 26 & 1.2 & NA \\
\hline 21 & Mesodorylaimus & 4 & 0 & Omnivores & 10.7 & 1.3 & 74.4 & NA \\
\hline
\end{tabular}

Note. APS-preplant sampling; AMS-midseason sampling; AHS-harvest sampling.

\subsection{Ecological Functions}

PPI/MI Ratio: We estimated the maturity index (MI: Bongers, 1990) and the plant parasite index (PPI) during all three sampling periods. The maturity index is an ecological measure of the state of succession, and is based on the composition of the free-living nematode fauna (C-p1-5), whereas the plant parasite index (PPI: Bongers and Korthals, 1995) is an indication of the level of nematode feeding on higher plants (P-p3-5). The PPI/MI ratio is inversely related and is a sensitive indicator of nutrient conditions in agro-ecosystems ((Bongers, 1990; Bongers \& Korthals, 1995; Bongers et al., 1997; Sieriebriennikov et al., 2014). It is, thus, used to monitor changes in the functioning of agricultural systems and natural habitats exposed to diffuse enrichment by N-deposition (Bongers et al., 1997; Yeates, 2003). Figures 1a and b illustrate the MI and PPI, respectively, during the sampling periods. The exact values calculated for the MI at harvest (AHS) and midseason (AMS) sampling according to Sieriebriennikov et al. (2014), were 2.20 and 1.73 and conversely for the PPI, the calculated values for AHS and AMS were 2.91 and 2.27, respectively. Both the PPI and MI indices increased from midseason to harvest and during these times the PPI calculated values were higher than their MI counterparts. For example, at harvest it was 2.91 versus 2.20 and at midseason it was 2.27 versus 1.73, given PPI/MI ratios of 1.32 and 1.31, respectively, for the harvest and midseason sampling periods. Higher PPI calculated values than MI values means that plant-parasitic nematode populations dominated the community of free-living nematodes (bacterivores, fungivores, and omnivores). Bacterivorous and fungivorous nematodes contribute to soil fertility (Ferris \& Matute, 2003; Neher, 2001; Chen \& Ferris, 2000; Ingham et al., 1985), therefore soils that create microenvironments conducive for the proliferation of bacterial and fungal feeding nematodes are desirable (Matute \& Anders, 2012). Also, omnivorous nematodes are suppressive to pest species, for example the plant-parasitic nematodes (Matute et al., 2013; Matute, 2013). The data suggest that low populations of free-living nematodes results in a low MI value and a high PPI value. This inverse relationship seems important 
in determining the pathogenicity and/or the proliferation of the parasitic nematodes.

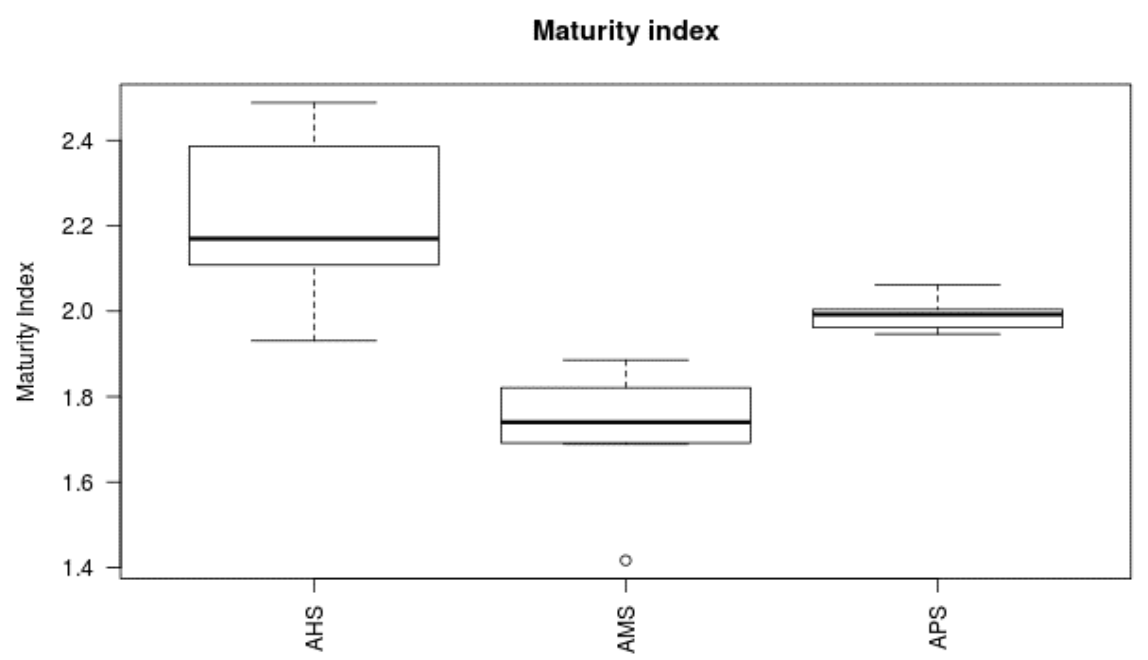

Figure 1a. An ecological measure of the state of succession of soil nematodes in Colfax wheat plots based on the composition of free-living nematodes fauna (C-p 1-5) (Maturity Index, MI)

Note. APS-preplant sampling; AMS-midseason sampling; AHS-harvest sampling.

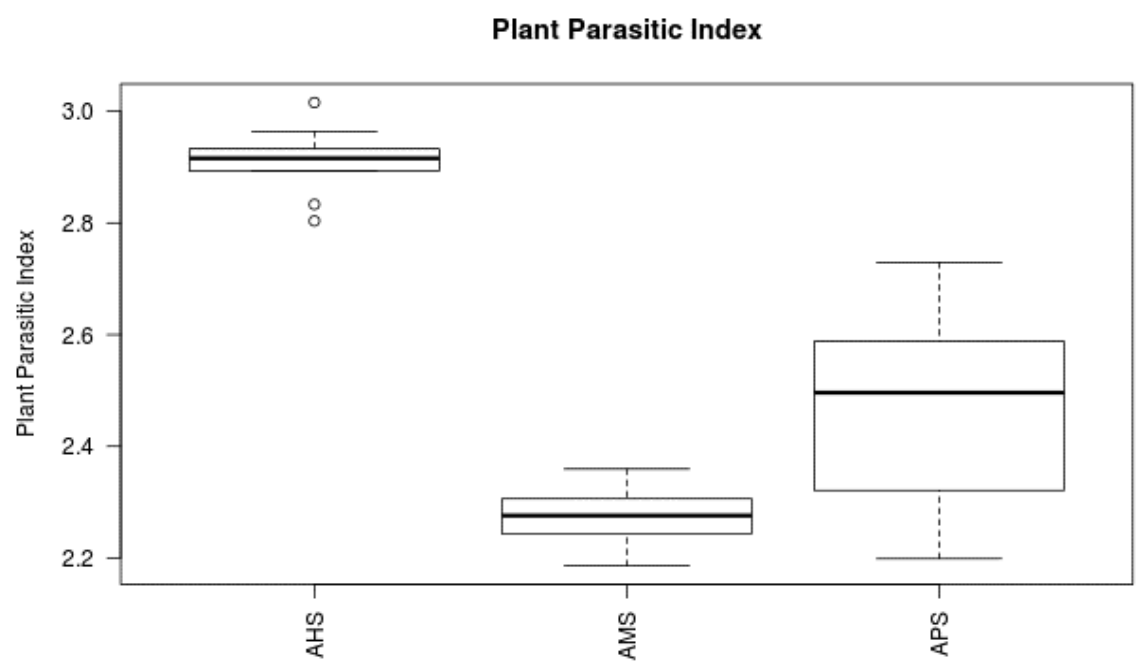

Figure 1b. An indication of the level of nematodes (P-p 3-5) feeding on root tissue in Colfax wheat plots (Plant Parasite Index, PPI)

Note. APS-preplant sampling; AMS-midseason sampling; AHS-harvest sampling.

Earlier studies (Bongers, 1990; Bongers \& Korthals, 1995) reported that a PPI/MI ratio greater than 1.6 disrupts nutrient uptake by plants, making nutrients (e.g. nitrogen) at least temporarily unavailable to plants. They reported a PPI/MI ratio of 0.9 as ideal for optimal nutrient uptake by plants. In our investigation, the PPI/MI ratios were 1.32 and 1.31, respectively, at harvest and during midseason. These values are higher than the ideal of 0.9 , which suggest that aside from being root tissue feeders, plant-parasitic nematodes were also a hindrance to nutrient uptake from the soil by the wheat plants. Farming methods that are conducive to the proliferation of free-living nematodes e.g. soft liable sources of nitrogen as soil amendments (Ferris \& Matute, 2003) are recommended. The data also shows that the initial PPI/MI ratio $(2.48 / 1.99=1.25)$ was higher than the ideal, which suggest that the initial plant-parasitic nematode populations in the wheat plots was high and this high 
population was more or less maintained throughout the growth of the wheat crop. A high initial plant-parasitic nematode population could be a result of successive or continuous growth of wheat in the same plots and/or other crops that are equally good host to the wheat parasitic nematodes. An appropriate crop rotation sequence and soil amendments that would reduce parasitic nematode populations and increase populations of free-living nematodes, could reverse the situation (Matute \& Anders, 2012; Ferris \& Matute, 2003).

Metabolic Footprint: A 'metabolic footprint' or exometabolome is a substance or metabolite released by a cell or an organism under controlled conditions and it is readily and accurately measurable (Douglas et al., 2005). Metabolic footprints of nematode assemblages provide measures of ecosystem services and functions performed by each functional guild (Ferris, 2010). The herbivore, bacterial, and fungal footprints are based on the nematode indicators of carbon and energy entering the soil food web through their respective channels. The structure footprints on the other hand is the metabolic footprint of higher trophic levels associated with a pest suppressive or regulatory function in the soil food web and which are indicative of the abundance of organisms of similar functions in non-nematode taxa (Ferris et al., 2001). Because the PPI/MI ratios for both the midseason and harvest sampling periods were similar, we combined the counts and then calculated their levels of carbon utilization in the food web. The data was grouped into similarity of function, for example, soil enrichment nematodes i.e. the bacterivores and fungivores (amplifiable prey), the herbivorous or plant-parasitic nematodes (target prey), and the pest suppressive or regulatory nematodes i.e. omnivores (predators). Their respective calculated metabolic footprints based on carbon utilization are illustrated in Figure $2 \mathrm{a}$. The data reveal that the target prey dominated in carbon utilization and therefore carbon entry into the soil food web. The carbon flow analysis in the wheat plots investigated as generated by the nematode faunal analysis by Sieriebriennikov et al. (2014) is illustrated in Figure 2b. Because soil microorganisms burn carbon as a source of energy, not all of the carbon a soil microorganism takes in remains in its body; a certain amount is lost as $\mathrm{CO}_{2}$ during respiration (Soils.usda.gov/sqi). Thus, in our investigation the plant-parasitic nematodes dominated the soil respiratory activities among the nematodes. The dominance of the target prey in carbon metabolism suggest that the low populations of the soil enrichment nematodes and the predatory nematodes resulted in an abundance of the target prey population, which may negatively affect the growth of wheat. The nature of this interaction between the free-living nematodes and the target prey populations resulted in their inverse relationship as measured by their $\mathrm{PPI} / \mathrm{MI}$ ratio.

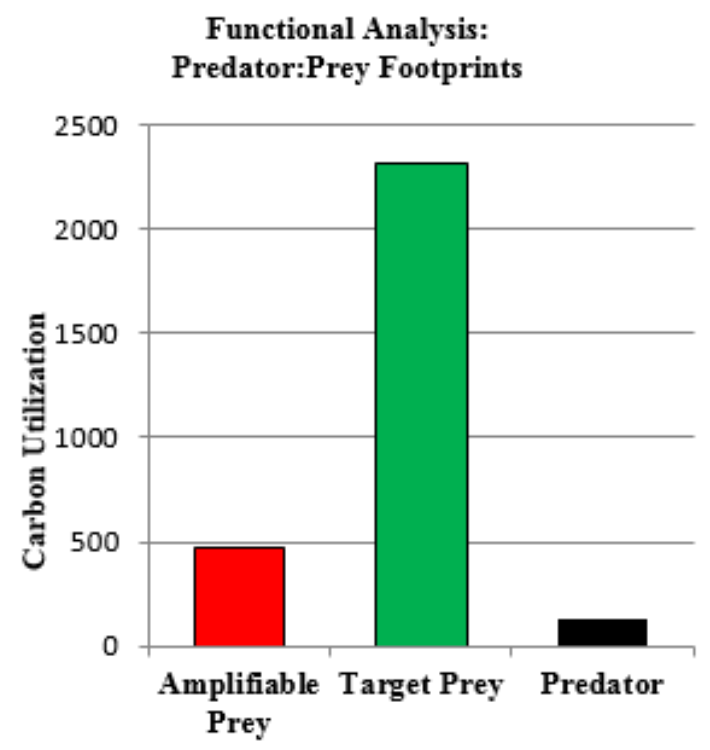

Figure 2a. Predator-Prey Relationships and Carbon flow during plant vigor (MS-Midseason + HS-Harvest) 
Carbon Flow Analysis

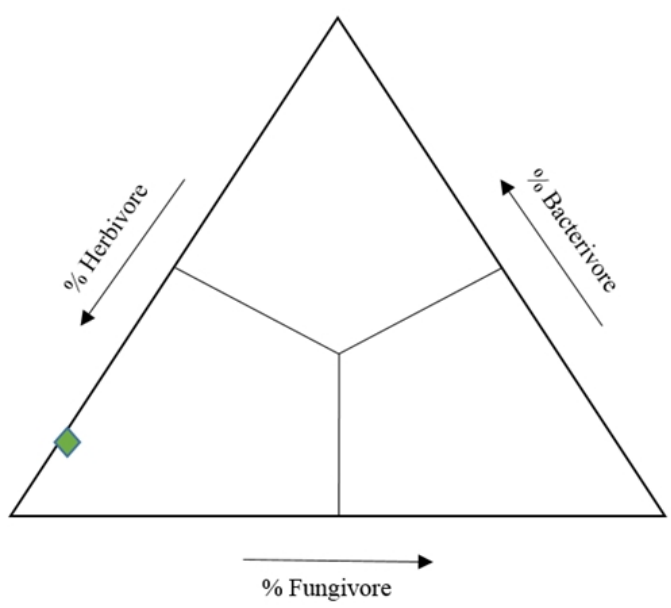

Figure 2b. An illustration of Carbon flow in the wheat plots investigated

\subsection{Soil Nematode Composition and Soil Conditions in the Wheat Plots Studied}

A previous study by Ferris et al. (2001) used the soil nematode community structure to analyze soil food web and to describe soil conditions. They developed a nematode faunal diagram to interpret their results: The soils are basal and degraded if the nematodes mapped at the lower left quadrat; The soils are disturbed and nitrogen enriched if they mapped at the upper left quadrat; the soils are maturing and recovering if the nematodes mapped at the upper right quadrat, and; the soils are matured, recovered and are stable, if the nematodes mapped at the lower right quadrat. Ferris et al. (2001) associated different C-p and P-p classes of nematodes with each of these conditions. We created a faunal diagram of the nematodes recovered using the Sieriebriennikov et al. (2014) program (see Figure 3a). Figure $3 b$ shows that at the start of the investigation (APS) the soil was described as "degraded basal soils", during mid-season sampling (AMS) the soil conditions changed to "enriched disturbed soils" and at harvest (AHS) the soil was tending towards being "structured". As nematode soil food web conditions change e.g. from basal (C-p2 nematodes of all trophic groups except the fungal feeding nematodes of the c-p2 class or $\mathrm{Fu}_{2}$ ) to enriched (i.e the bacterivorous nematodes of the c-p1 class or $\mathrm{Ba}_{1}$ and fungal feeding nematodes of the $\mathrm{Fu}_{2}$ ), and then to structured (C-p 3-5 nematodes of all trophic levels), there is a succession of different nematode groups with different functions (Ferris and Matute, 2003). Succession, however, does not mean the elimination of a previous feeding group, it simply means the food web becomes more speciose (Ferris et al., 2001) and is a continuum. In our investigation at harvest we had a partially structured soil, short of the structured and matured soils (Cp3-5 nematodes) that are described as pest suppressive soils. This is thought to be a possible contributory factor to the high populations of plant-parasitic nematodes at harvest. To further demonstrate the overall soil conditions based on the entire assemblage of the nematode composition, a food web diagnostic faunal graph was generated using the Sieriebriennikov et al. (2014) program (see Figure 3b). Figure $3 \mathrm{~b}$ clearly demonstrates that the concentration and mapping of the nematodes on the graph reveal that the wheat plots were stressed soils. Our data seem to suggest that stressed soils are associated with high populations of the plant-parasitic nematodes as compared to the free-living nematodes, especially the pest suppressive species. This is further demonstrated by the high PPI/MI ratio obtained. While the overall conditions of the soils are described as 'stressed', there were observed changes during the growth stages i.e. basal at preplant (APS), enriched at mid-season (AMS), and partial maturing at harvest (AHS). Thus nematodes are good biomonitors of soil conditions and changing soil conditions (Ferris et al. 2001). 


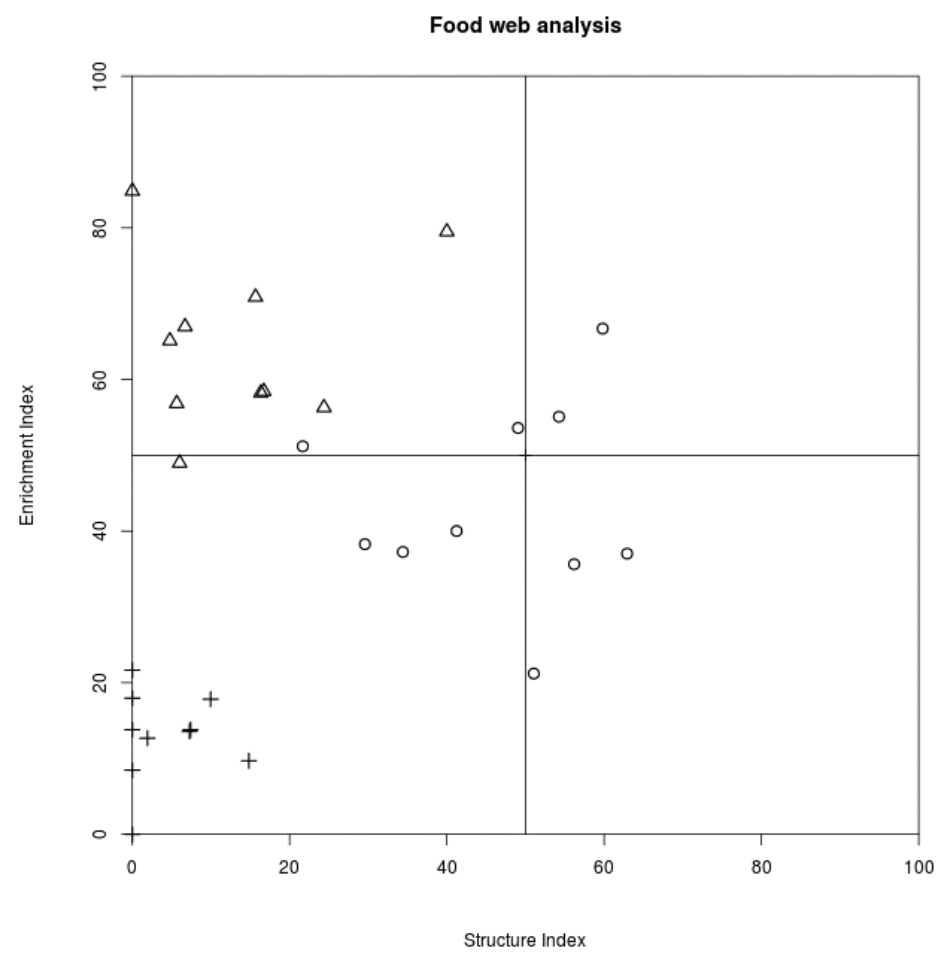

Figure 3a. Faunal diagram analysis of the nematodes recovered from the Colfax wheat plots. The faunal diagram combines the harvest (AHS), midseason (AMS) and preplant (APS) conditions

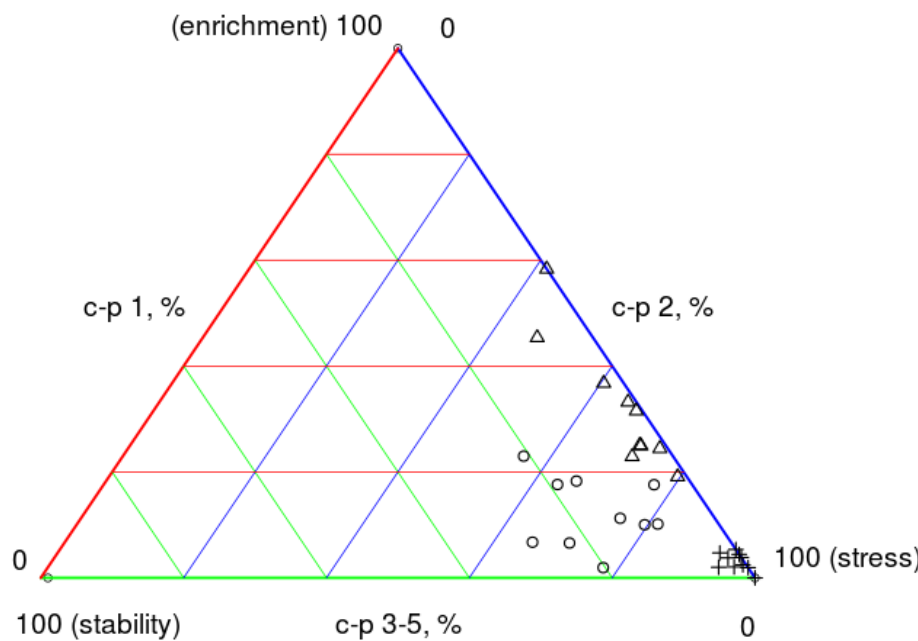

Figure $3 b$. Food web diagnostic of wheat plots sampled in Colfax

Note. APS-preplant sampling; AMS-midseason sampling; AHS-harvest sampling.

\subsection{Composition of Soil Nematodes in Colfax Wheat Plots}

Four feeding groups of nematodes were recovered: The omnivores, bacterivores, fungivores, and herbivores or plant-parasites (Figure 4). 


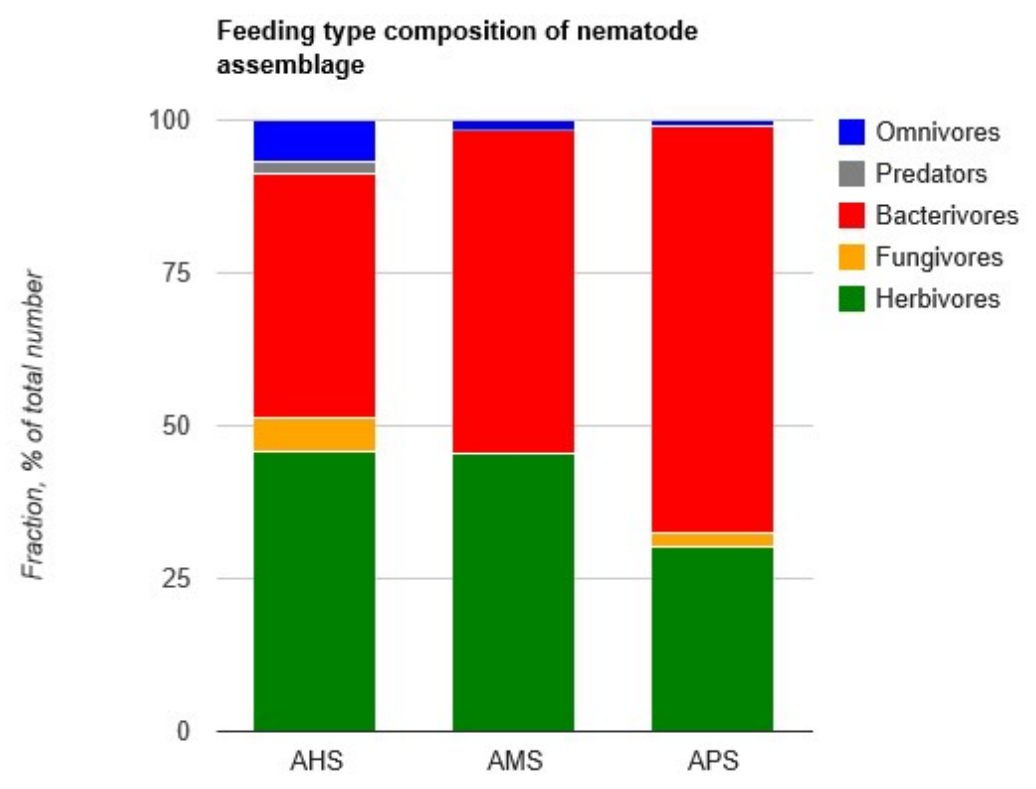

Figure 4. Proportions of soil nematodes recovered from Colfax wheat plots according to feeding types

Omnivorous Nematodes: Structured soils (i.e. maturing and matured soils) have an increasing number of free-living nematodes in the c-p 3-5 classes. The omnivorous nematodes (pest suppressive species) recovered in this investigation were of the c-p4 class. By mid-season (AMS), they were two and half times the initial population (28.8/11.7) and by harvest (AHS), their population was over eight times the initial population (96.9/11.7) (Figure 4; Figure 5a). Clearly the soil was tending towards stability, accommodating these higher levels of nematodes that are sensitive to disturbances. This is a reiteration of Figure 3a, depicting a soil that was maturing with a continuum of nematode species.

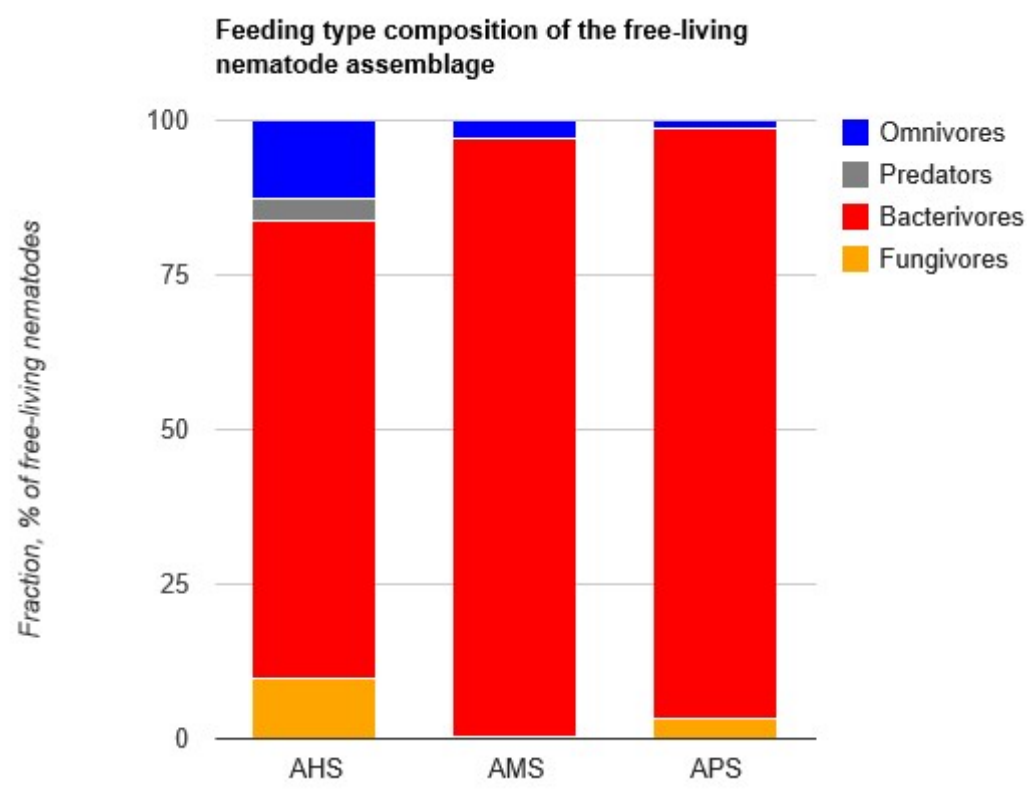

Figure 5a. Proportions of free-living soil nematodes recovered from Colfax wheat plots according to feeding groups

Note AHS $=$ Harvest AMS $=$ Midseason; APS $=$ Preplant. 
Bacterial Feeding Nematodes: Among the free-living nematodes, bacterial feeding nematode populations dominated during all sampling periods (Figure 5a). Six taxa of bacterivores nematodes were recovered (Table 1). During plant vigor (AMS and AHS), bacterivorous nematodes of the class c-p2 or $\mathrm{Ba}_{2}$, represented by the families Cephalobidae (Acrobeloides, Cephalobus) and Plectidae (Plectus), dominated. Bacterial feeding nematodes of the C-p2 class are associated with basal and degraded soil conditions. The dominance of the C-p2 nematodes is further demonstrated by Figure $5 \mathrm{~b}$. In our investigation the dominance of these nematodes is what is illustrated in Figure $3 \mathrm{~b}$ as stressed soils. Figure 5a also illustrates the suppressive nature of the omnivorous nematodes. Populations of the bacterivorous nematodes reduced at harvest (AHS) as compared to the mid-season (AMS) and preplant (APS) sampling periods, with an increase in the populations of the omnivorous nematodes.

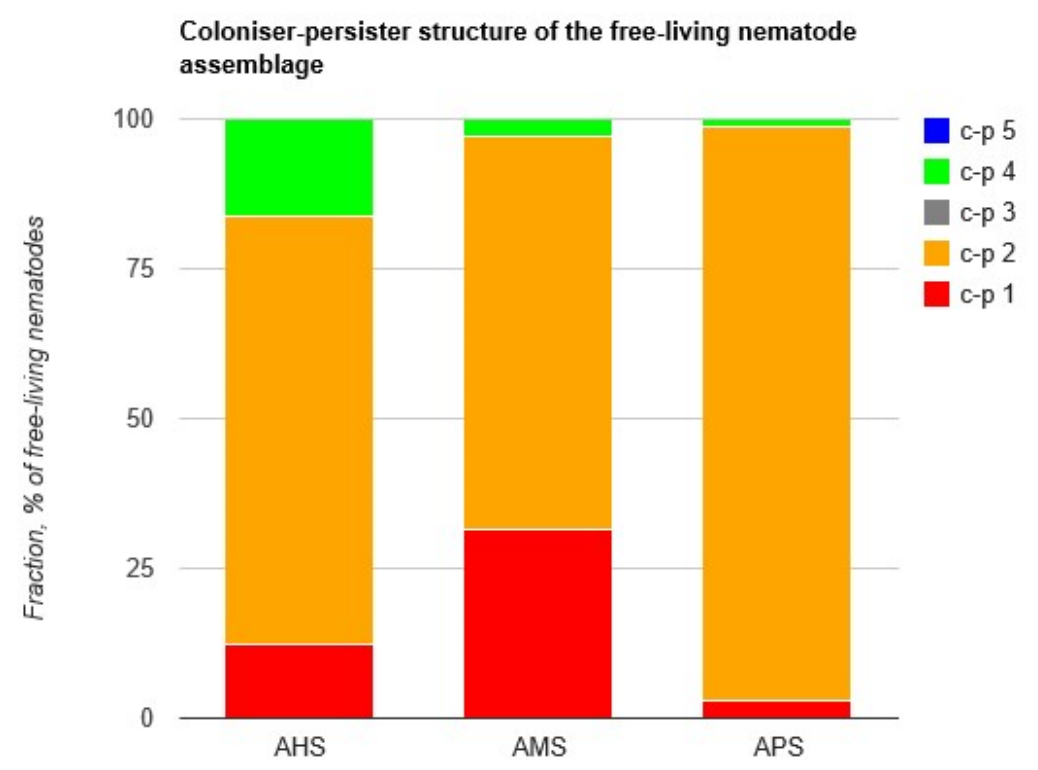

Figure 5b. Dominance of C-p2 nematodes in the Colfax wheat plots sampled

Note. AHS $=$ Harvest; AMS $=$ Midseason; APS $=$ Preplant.

Plant-Parasitic Nematodes: Based on feeding behavior, six plant-parasitic nematode assemblages were recovered for a total of 10 plant-parasitic nematode taxa and of these, six were of the plant-parasite class 3 or P-p3 class (Figure 6a). The P-p3 nematodes were dominated by the sedentary nematodes (Heterodera; Table 1). This dominance is further illustrated in Figure 6b. Helicotylenchus has been reported feeding from single nonhypertrophied cells as sedentary semi-endoparasites for 20 days (Subbotin, 1993). The sedentary endoparasites are reported as having the most complex interaction with their host, and are thought to be responsible for the majority of the agricultural damage (Tytgat \& De Meutter, 2000). From an abundance perspective, the cyst nematodes Heterodera are of the most concern in the Colfax wheat plots, corroborating earlier studies (Smiley et al., 2004, 2005, 2012) in which these cysts nematodes were documented being of concern in the production of wheat in the PNW. 


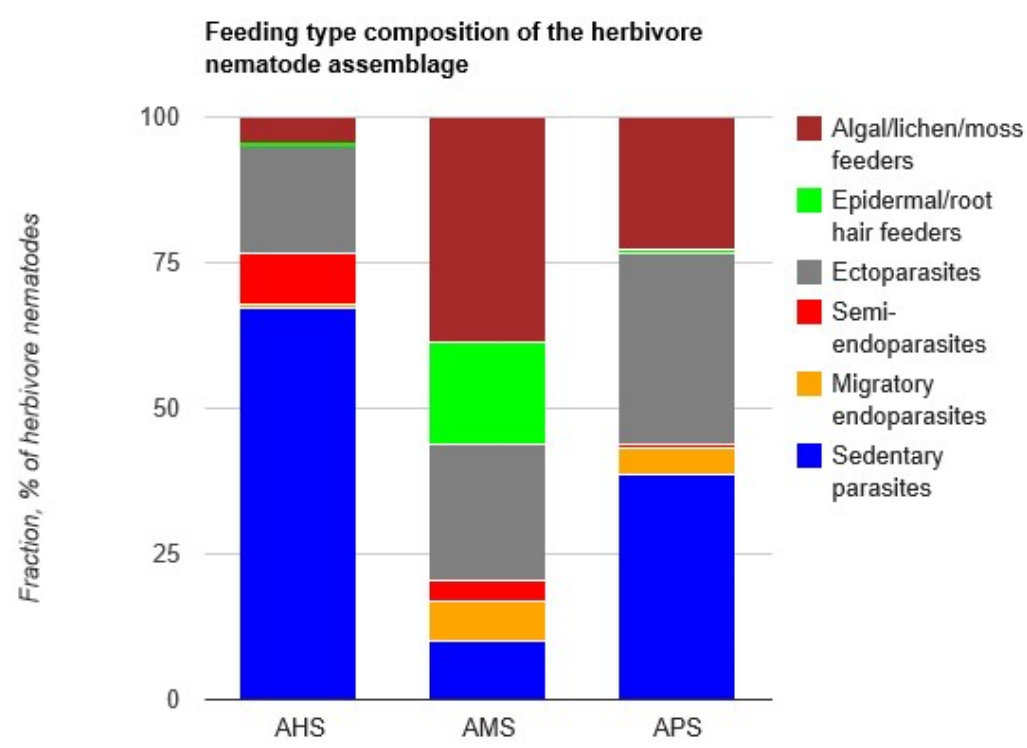

Figure 6a. Composition of the plant-parasitic nematodes recovered in Colfax wheat plots according to feeding groups

Note. AHS=Harvest; AMS $=$ Midseason; APS $=$ Preplant.

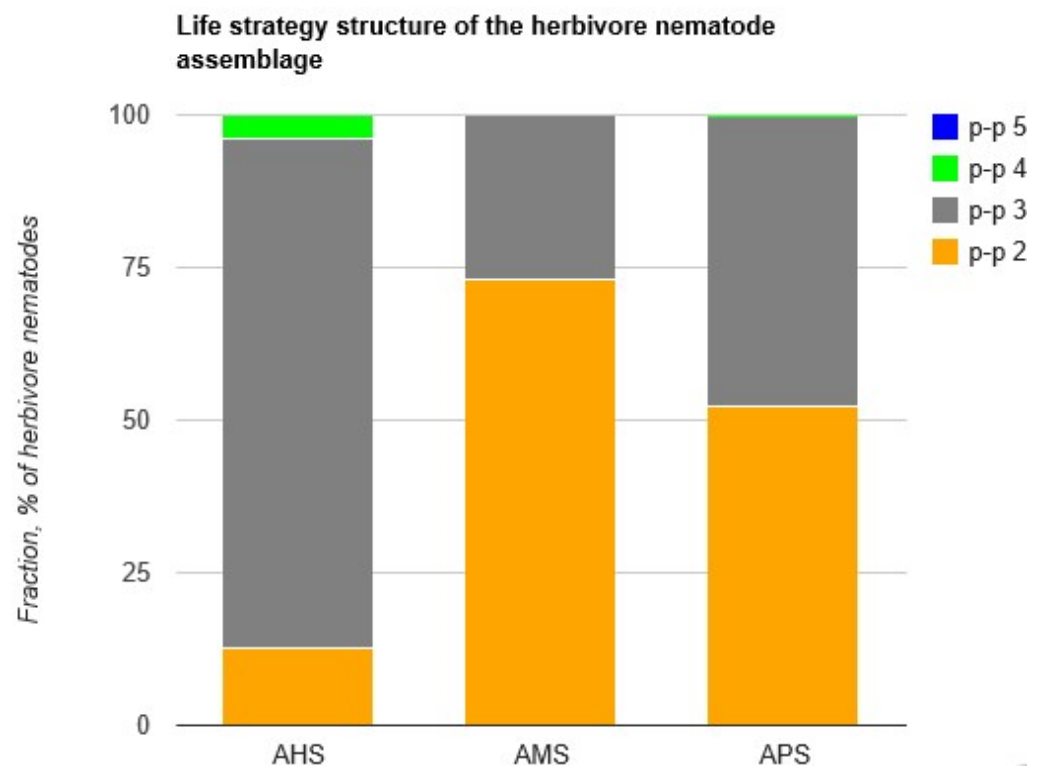

Figure 6b. Proportions of the plant parasitic nematodes recovered from Colfax wheat plots according to P-p classes

Note . AHS $=$ Harvest AMS $=$ Midseason; APS $=$ Preplant.

\section{Conclusion}

1) The abundance of plant-parasitic nematodes in the wheat plots sampled suggests that herbivorous nematodes are an economic problem to sustainable and profitable wheat production in the study plots. The P-p3 classes of parasitic nematodes dominated, and were in turn dominated by sedentary nematodes, mostly Heterodera.

2) Because the plant-parasitic nematodes dominated other nematode groups, the PPI/MI ratio was higher than the ideal that ensure an optimal nutrient uptake by plant roots, further compounding the problem. 
3) Overall, the soils in the plots sampled are stressed and degraded. Their conditions will be improved if the populations of free-living nematodes increased. This will require a change in the farming methods e.g. rotations and organic soil amendments.

4) Conditions in the Colfax wheat plots changed from basal at preplant, to enriched at midseason, and then tended towards maturing at harvest, reflecting the changing complexity of the nematode food web during the respective periods.

5) Our investigation has reiterated the necessity to study the entire soil nematode community structure in farming systems and in the monitoring of soil conditions.

\section{Acknowledgements}

This investigation was sponsored in part by the National Research Initiative Competitive Grants CAP Project (2011-68002-30029) from the USDA National Institute of Food and Agriculture.

\section{References}

Barker, K. R. (1985). Nematode extraction and bioassays. In K. R. Barker, C. C. Carter, \& S. N. Sasser (Eds.), An advanced treatise on Meloidogyne (Vol. 2, pp. 19-35). North Carolina State University Graphics, Raleigh, North Carolina. http://dx.doi.org/10.1111/j.1751-7915.2012.00342.x.

Bongers, T. (1990). The maturity index an ecological measure of environmental disturbance based on nematode species composition. Oecologia, 83, 14-19: http://dx.doi.org/10.1007/BF00324627

Bongers, T., \& Bongers, M. (1998). Functional diversity of nematodes. Applied Soil Ecology, 10(3), 239-251. http://dx.doi.org/10.1016/S0929-1393 (98)00123-1

Bongers, T., \& Ferris, H. (1999). Nematode community structure as a bioindicator in environmental monitoring. Trends in Ecology and Evolution, 14, 224-228. http://dx.doi.org/10.1094/PHP-2003-1120-01-RS

Bongers, T., van der Meulen, H., \& Korthals, G. (1997). Inverse relationship between the nematode maturity index and the plant parasite index under enriched conditions. App. Soil Ecol., 6, 195-199. http://dx.doi.org/10.1016/S0929-1393 (96)00136-9

Chen, J., \& Ferris, H. (1999). The effects of nematode grazing on nitrogen mineralization during fungal decomposition of organic matter. Soil Biol. Biochem., 31, 1265-1279. http://dx.doi.org/10.1094/PHP-2003-1120-01-RS

Chen, J., \& Ferris, H. (2000). Growth and nitrogen mineralization of selected fungi and fungal-feeding nematodes on sand amended with organic matter. PI. Soil, 218, 91-101. http://dx.doi.org/10.1094/PHP-2003-1120-01-RS

Ferris, H. (2010). Form and Function: Metabolic footprints of nematodes in the soil food web. European Journal of Soil Biology, 46, 97-104. http://dx.doi.org/10.1016/j.ejsobi.2010.01.003

Ferris, H., \& Matute, M. M. (2003). Structural and functional succession in the nematode fauna of a soil food web. Applied Soil Ecology, 23, 93-110. http://dx.doi.org/10.1016/S0929-1393 (03)00044-1

Ferris, H., Bongers, T., \& de Goede, R. G. M. (2001). A framework for soil food web diagnostics: Extension of the nematode faunal analysis concept. Applied Soil Ecology, 18, 13-29. http://dx.doi.org/10.1016/S0929-1393 (01)00152-4

Handoo, Z. A. (1998). Crop yields and nematode population densities in triticale-cotton and triticale-soybean rotations. Journal of Nematology, 30(3), 353-361.

Ingham, R. E., Trofymow, J. A., Ingham, E. R., \& Coleman, D. C. (1985). Interactions of bacteria, fungi and their nematode grazers: Effects on nutrient cycling and plant growth. Ecological Monographs, 55, 119-140. http://dx.doi.org/10.2307/1942528

Kronstad, W. E., Rohde, C. R., Kolding, M. F., \& Metzger, R. J. (1978). Registration of Stephens Wheat. Crop Science, 18(6), 1097. http://dx.doi.org/10.2135/cropsci1978.00111800060060x.

Matute, M. M., \& Anders, M. (2012). Influence of rice rotation systems on soil nematode trophic groups in Arkansas. Journal of Agricultural Science, 4(2), 11-20. http://dx.doi.org/10.5539/jas.v5n1p44

Matute, M. M., Manning, Y. A., \& Kaleem, M. I. (2013). Community structure of soil nematodes associated with Solanum tuberosum. Journal of Agricultural Science, 5(1), 44-52. http://dx.doi.org/10.5539/jas.v5n1p44

Matute, M. M. (2013). Soil nematodes of Brassica rapa: Influence of temperature and pH. Advances in Natural Science, 6(4), 20-26. http://dx.doi.org/10.3968\%2Fj.ans.1715787020130604.2858 
Neher, D. A. (2001). Role of nematodes in soil health and their use as indicators. Journal of Nematology, 33, 161-168. http://dx.doi.org/10.1016/j.pedobi.2015.04.003

Nicol, J. M., Turner, S. J., Coyne, D. L., den Nijs, L., Hockland, S., \& Maafi, T. (2011). Current Nematode Threats to World Agriculture. In J. T. Jones, G. Gheysen, \& C. Fenoli (Eds.), Genomics and Molecular Generics of Plant Nematode Interactions (pp. 21-43). Springer, Dordrecht, The Netherlands. http://dx.doi.org/10.1007/978-94-007-0434-3_2

Sasser, J. N. (1989). Plant-parasitic Nematodes: The Farmer's Hidden Enemy (p. 15). North Carolina State University Graphics, Raleigh, North Carolina. http://dx.doi.org/10.11646/zootaxa.3785.4.6

Sieriebriennikov, B., Ferris, H., \& de Goede, R. G. M. (2014). NINJA: An automated calculation system for nematode-based biological monitoring. European Journal of Soil Biology, 61, 90-93. http://dx.doi.org/10.1016/j.ejsobi.2014.02.004

Smiley, R. W., Merrifield, K., Patterson, L. M., Whittaker, R. G., Gourlie, J. A., \& Easley, S. A. (2004). Nematodes in dryland field crops in the semiarid Pacific Northwest United States. Journal of Nematology, 36(1), 54-68. http://dx.doi.org/10.1094/PDME01

Smiley, R. W., Whittaker, R. G., Gourlie, J. A., Easley, S. A., \& Ingham, R. E. (2005). Plant-parasitic nematodes associated with reduced wheat yield in Oregon: Heterodera avenae. Journal of Nematology, 37(3), $297-307$. http://dx.doi.org/10.1094/PDME01

Smiley, R. W., Gourlie, J. A., Rhinhart, K. E. L., Marshall, J. M., Anderson, M. D., \& Yan, G. P. (2012). Influence of nematicides and fungicides on spring wheat in fields infested with soilborne pathogens. Plant Disease, 96, 1537-1547. http://dx.doi.org/10.1094/PDIS-02-12-0165-RE

Subbotin, S. A. (1993). Evolution of modified food cells induced by sedentary nematodes in plant roots. Russian Journal of Nematology, 1(1), 17-26.

Stirling, G. R., Nicol, J. M., \& Reay, F. (1998). Advisory services for nematodes pests - operational guide (p. 120). Rural Industries Research and Development Corporation Publication No. 99/41. Canberra. http://dx.doi.org/10.1007/978-81-322-1841-8_2

Tytgat, T., \& De Meutter, J. (2000). Sedentary endoparasitic nematodes as a model for other plant-parasitic nematodes. Nematology, 2(1), 113-121. http://dx.doi.org/10.1163/156854100508827

Whitehead, A. G. (1998). Plant nematode control. Wallingford, UK, CAB.

Yan, G. P., Smiley, R. W., Okubara, P. A., \& Skantar, A. M. (2013). Species-specific PCR assays for differentiating Heterodera filipjevi and $H$. avenae. Plant Disease, 97, 1611-1619. http://dx.doi.org/10.1094/PDIS-01-13-0064-RE

Yeates, G. W. (2003). Nematodes as soil indicators: Functional and biodiversity aspects. Biol. Fert Soils, 37, 199-210. http://dx.doi.org/10.1007/s00374-003-0586-5

\section{Copyrights}

Copyright for this article is retained by the author(s), with first publication rights granted to the journal.

This is an open-access article distributed under the terms and conditions of the Creative Commons Attribution license (http://creativecommons.org/licenses/by/3.0/). 